\title{
PEMANFAATAN MATERIAL LOKAL DENGAN PERKUATAN CFRP UNTUK PENANGANAN LONGSOR DI WILAYAH BALIKPAPAN KALIMANTAN TIMUR
}

\author{
Karmila Achmad $^{1 *}$, Sara Wibawaning Respati ${ }^{2}$, Sunarno ${ }^{3}$. \\ 1, 2 dan 3 Jurusan Teknik Sipil , Politeknik Negeri Balikpapan \\ *email:milabpp@yahoo.co.id
}

\begin{abstract}
Balikpapan, East Borneo gateway, is a city that grows rapidly. There has been infrastructure expansions in both city centre and away from the city. Nevertheless, based on hazard index map, Balikpapan soil condition is belong to highly vulnerable area for floods and landslides disaster. CFRP material is a material that is still slightly used in Balikpapan. This condition appears because the lack of researches of this material to overcome the structure problem in Balikpapan. So that, because of landslides threat, a breakthrough in the form of research that is able to provide solutions to disaster management is a certain needed. The result of the study showed that the average concrete strength for 28 days of age is 18,87 MPa, 20,00 MPa; 21,89 MPa; 22,27 MPa; 22,65 MPa; 17,74 MPa; 18,87 MPa; 20,38 MPa and 23,02 MPa for BN, O0, O2, O3, O7, T2, T3, T5 and TF specimens respectively. The percentage of the concrete strength increment compared to normal concrete 28 days of age is $6 \% ; 16 \% ; 18 \% ; 20 \% ; 2,12 \% ; 8,64 \% ; 17,33 \%$ and 32,54\% for O0, O2, O3, O7, T2, T3, T5 and TF specimens respectively. The full jacketing specimen with CFRP has proved that CFRP can increase the concrete strength even not as big as compared to CFRP ability to retain the concrete tensile and ductility.
\end{abstract}

Keywords : Local Material, Structure Strengthen, Carbon Fiber Reinforced Polymer (CFRP)

\begin{abstract}
Abstrak
Balikpapan sebagai pintu gerbang Kalimantan Timur merupakan kota yang sedang berkembang pesat. Banyak pembangunan yang dilakukan, baik dipusat kota maupun pengembangan kearah luar kota. Namun berdasarkan peta indeks rawan bencana, kondisi tanah di Balikpapan termasuk dalam kondisi yang sangat rawan bencana (kategori berat) untuk bencana banjir dan longsor. Material CFRP merupakan material yang belum banyak dimanfaatkan di wilayah Balikpapan.Hal ini karena kurangnya penelitian mengenai aplikasi material ini untuk menangani permasalahan struktur yang ada di Balikpapan.Sehingga dengan adanya masalah longsor maka perlu sebuah terobosan berupa penelitian yang mampu memberikan solusi terhadap penanganan bencana tersebut.Maka perlu penelitian mengenai "pemanfaatan material lokal dengan perkuatan CFRP untuk penanganan longsor di wilayah Balikpapan, Kalimantan Timur. Dari hasil pengujian diperoleh nilai kuat tekan rata-rata beton umur 28 hari adalah $18,87 \mathrm{MPa}$; 20,00 $\mathrm{MPa}$; 21,89 $\mathrm{MPa}$; 22,27 $\mathrm{MPa}$; 22,65 $\mathrm{MPa}$; $17,74 \mathrm{MPa}$; 18,87 MPa; 20,38 MPa dan 23,02 MPa masing-masing untuk benda uji BN, O0, O2, O3, O7, T2, T3, T5 dan TF. Dengan prosentase peningkatan kuat tekan terhadap beton normal pada umur beton 28 hari adalah 6\%; 16\%; 18\%; 20\%; 2,12\%; 8,64\%; 17,33\% dan 32,54\% masing-masing untuk benda uji O0, O2, O3, O7, T2, T3, T5 dan TF. Benda uji full jacketing dengan CFRP terbukti mampu meningkatkan kuat tekan beton meskipun hasilnya tidak sebesar kemampuan CFRP menahan tarik atau daktilitas beton.
\end{abstract}

Kata Kunci : Material Lokal, Perkuatan Struktur dan Carbon Fiber Reinforced Polymer (CFRP) 


\section{Pendahuluan}

Balikpapan sebagai pintu gerbang Kalimantan Timur merupakan kota yang sedang berkembang pesat. Banyak pembangunan yang dilakukan, baik dipusat kota maupun pengembangan kearah luar kota.Namun berdasarkan peta indeks rawan bencana, kondisi tanah di Balikpapan termasuk dalam kondisi yang sangat rawan bencana (kategori tinggi) untuk bencana banjir dan longsor.

Ada beberapa titik yang diwaspadai karena sangat rawan terjadinya bencana banjir dan tanah longsor diantaranya, wilayah Damai Balikpapan Selatan, daerah Kantor Sosial Balikpapan Utara dan Tugu Adipura Gunung Sari Balikpapan Tengah. Berarapa daerah perbukitan yang paling diwaspadai untuk tanah longsor yaitu wilayah Prapatan Balikpapan Selatan, Martadinata Balikpapan Tengah, Gunung Empat Wilayah Balikpapan Utara dan beberapa wilayah Balikpapan Utara.

Salah satu material pembentuk beton adalah agregat halus. Dalam penelitian ini akan digunakan pasir samboja. Pasir samboja merupakan material lokal yang saat ini dominan dipakai di Balikpapan karena butirannya yang halus.Penelitian pendahuluan berupa pemanfaatan pasir samboja sebagai campuran beton normal telah dilakukan dan terbukti bahwa pasir samboja memiliki kekuatan yang tinggi (Sunarno, 2012).

\section{Dinding Penahan Tanah}

Bangunan dinding penahan tanah digunakan untuk menahan tekanan tanah lateral yang ditimbulkan oleh tanah urug atau tanah asli yang labil. Bangunan ini banyak digunakan pada proyek-proyek irigasi, jalan raya, pelabuhan dan lainlain.Kestabilan dinding penahan tanah diperoleh terutama dari berat sendiri struktur dan berat tanah yang berada di atas pelat pondasi. Besar dan distribusi tekanan tanah pada dinding penahan tanah sangat bergantung pada gerakan kea rah lateral tanah relative terhadap dinding.

\section{Carbon Fiber Reinforced Polymer (CFRP)}

Serat karbon didefinisikan sebagai serat yang mengandung setidaknya $90 \%$ berat karbon.Digunakan fiber graphite yang merupakan serat dengan karbon diatas $95 \%$ beratnya. Yang paling umum digunakan adalah poliakrilonitril (PAN), (petroleum) minyak bumi, serat selulosa(Viscose rayon, katun) dan fiberphenolic tertentu. Komposit serat karbon cocok untuk aplikasi yang harus memenuhi persyaratan kekuatan, kekakuan, ringan dan ketahanan terhadap fatigue. Tidak seperti serat kaca dan aramid, serat karbon tidak menunjukkan korosi atau pecah pada suhu kamar. Selain itu karbon juga dapatdigunakan dalam aplikasi yang memerlukan ketahanan suhu tinggi, kelembaman dan redaman.

Serat karbon memiliki kekuatan yang relatif lebih tinggi dibanding serat kaca. Sehingga material ini cocok digunakan untuk perkuatan struktur beton (Lignola, 2005).

\section{Metoda Penelitian}

Dalam penelitian ini akan dibuat 54 benda uji silinder yang akan diuji umur 14 hari dan 28 hari. Ada 3 kelompok benda uji yang digunakan yaitu kelompok benda uji original, variasi overlap dan variasi tebal CFRP. Dari kelompok benda uji ini dibagi dalam 9 jenis variasi benda uji, yaitu : jenis variasi beton normal $(\mathrm{BN})$, overlap $0 \mathrm{~cm}(\mathrm{O} 0)$, overlap $2 \mathrm{~cm}(\mathrm{O} 2)$, overlap $3 \mathrm{~cm}$ (O3), overlap $7 \mathrm{~cm}$ (O7), tebal $2 \mathrm{~cm}$ (T2), tebal $3 \mathrm{~cm}$ (T3), tebal 5 cm (T5), full jacketing (TF), seperti ditunjukan pada tabel 1 dan gambar 1. 
Tabel 1. Rincian Benda Uji

\begin{tabular}{|c|c|c|c|}
\hline $\begin{array}{c}\text { Kel. } \\
\text { Benda } \\
\text { Uji }\end{array}$ & Jenis variasi & $\begin{array}{c}\text { Kode } \\
\text { Penamaan }\end{array}$ & Ket \\
\hline Original & $\begin{array}{c}\text { Beton } \\
\text { normal }\end{array}$ & BN1 - BN6 & $\begin{array}{l}\text { Mix } \\
\text { design } \\
\text { menggun } \\
\text { akan } \\
\text { metode } \\
\text { SNI } \\
\text { 03- } \\
2834- \\
2000\end{array}$ \\
\hline \multirow{4}{*}{$\begin{array}{l}\text { Variasi } \\
\text { overlap }\end{array}$} & overlap : $0 \mathrm{~cm}$ & O01 -O06 & \multirow{4}{*}{$\begin{array}{l}\text { Space : } 5 \\
\text { cm dan } \\
\text { tebal : } 3 \\
\mathrm{~cm}\end{array}$} \\
\hline & overlap : $2 \mathrm{~cm}$ & $\mathrm{O} 21-\mathrm{O} 26$ & \\
\hline & overlap : $3 \mathrm{~cm}$ & $\mathrm{O} 31-\mathrm{O} 36$ & \\
\hline & overlap : $7 \mathrm{~cm}$ & O71 -O76 & \\
\hline \multirow{4}{*}{$\begin{array}{c}\text { Variasi } \\
\text { tebal } \\
\text { CFRP }\end{array}$} & $\begin{array}{c}\text { tebal CFRP : } 2 \\
\mathrm{~cm}\end{array}$ & T21-T26 & \multirow{4}{*}{$\begin{array}{l}\text { Space : } 5 \\
\text { cm dan } \\
\text { overlap : } \\
5 \mathrm{~cm}\end{array}$} \\
\hline & $\begin{array}{c}\text { tebal CFRP : } 3 \\
\mathrm{~cm}\end{array}$ & T31-T26 & \\
\hline & $\begin{array}{c}\text { tebal CFRP : } 5 \\
\mathrm{~cm} \\
\end{array}$ & T51-T56 & \\
\hline & $\begin{array}{l}\text { Full jacketing } \\
\text { CFRP }\end{array}$ & TF1-TF6 & \\
\hline
\end{tabular}

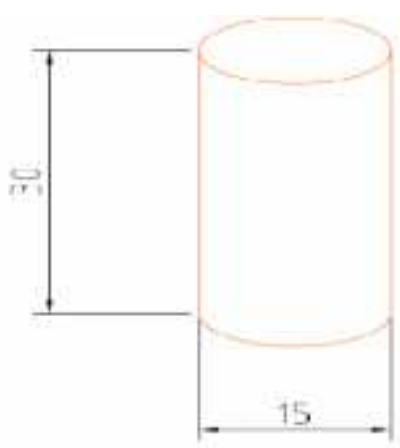

(a) $\mathrm{BN}$

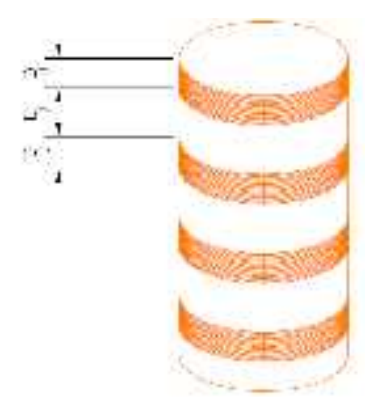

(b) $\mathrm{O} 0$

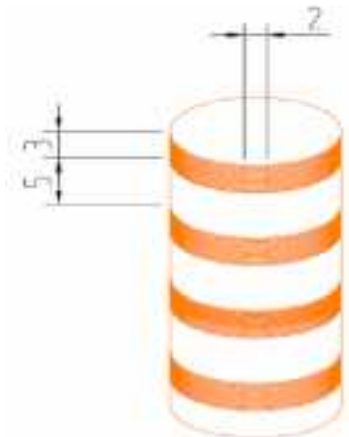

(c) $\mathrm{O} 2$

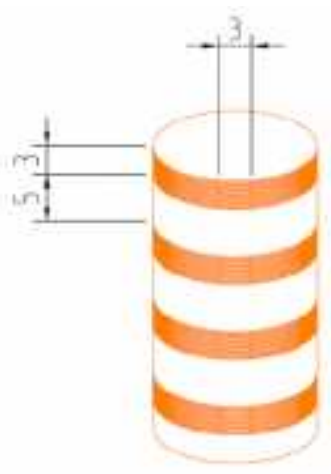

(d) $\mathrm{O} 3$

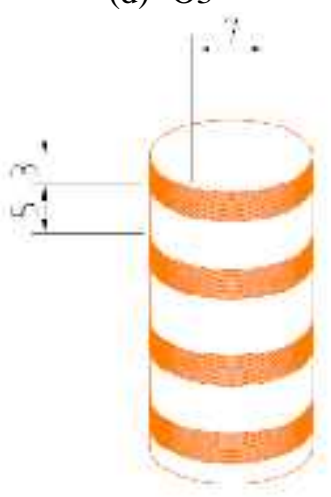

(e) $\mathrm{O} 7$

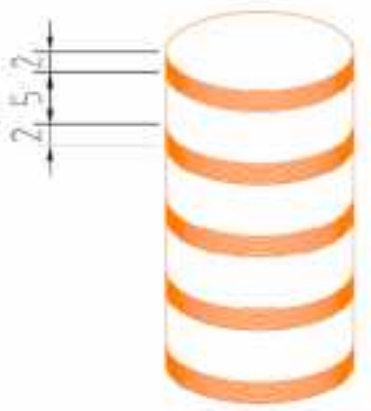

(f) $\mathrm{T} 2$ 


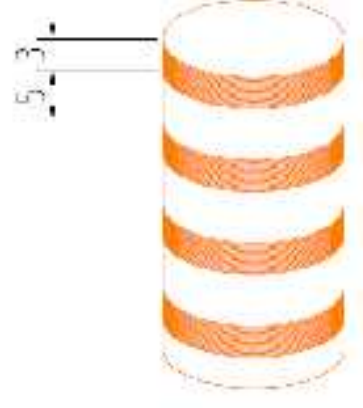

(g) T3

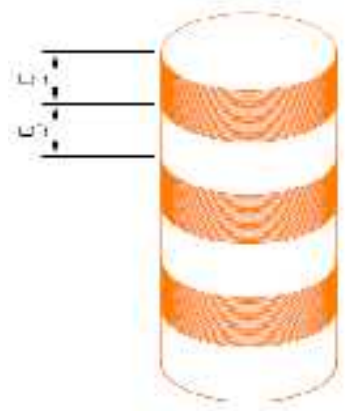

(h) $\mathrm{T} 5$

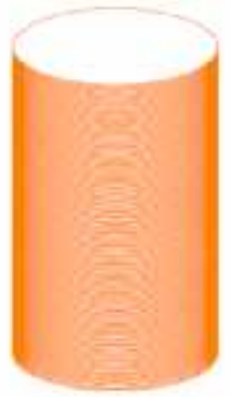

(i) $\mathrm{TF}$

Gambar 1. Rencana Benda Uji

\section{Hasil Penelitian}

\subsection{Hasil Kuat Tekan Umur 14 Hari}

Dari hasil uji tekan beton umur 14 hari maka diperoleh nilai kuat tekan beton terbesar adalah untuk benda uji dengan fully jacketing CFRP sebesar 23,16 $\mathrm{MPa}$ dengan peningkatan kuat tekan beton sebesar 33,33\% terhadap beton normal $\mathrm{BN}$, seperti ditunjukan dalam gambar 2 .

Nilai kuat tekan rata-rata beton umur 14 hari adalah $17,37 \mathrm{MPa}$; $18,87 \mathrm{MPa}$; 20,37 MPa; 20,80 MPa; 21,02 MPa; 17,80 $\mathrm{MPa} ; 18,66 \mathrm{MPa} ; 20,80 \mathrm{MPa}$ dan 23,16
MPa masing-masing untuk benda uji BN, O0, O2, O3, O7, T2, T3, T5 dan TF.

Dengan prosentase peningkatan kuat tekan terhadap beton normal pada umur beton 14 hari adalah 8,64\%; 17,28\%; $19,75 \% ; 20,99 \% ; 2,47 \% ; 7,41 \% ; 19,75 \%$ dan $33,33 \%$ masing-masing untuk benda uji O0, O2, O3, O7, T2, T3, T5 dan TF.

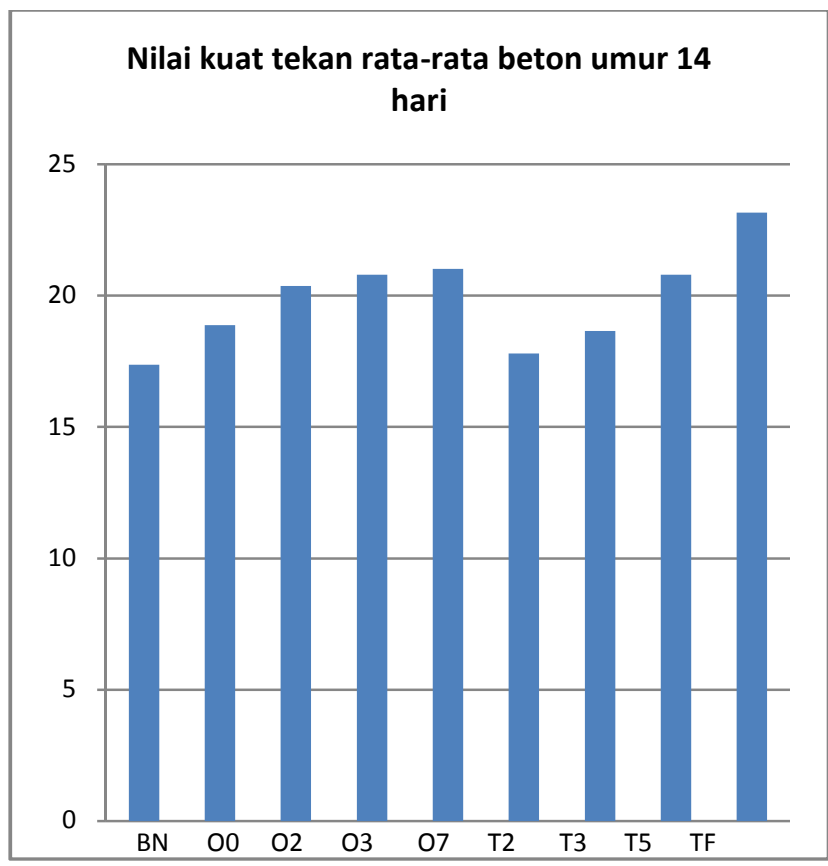

Gambar 2. Grafik Nilai Kuat Tekan Beton Umur 14 Hari

Kerusakan beton normal terjadi pada cover beton sepanjang tinggi benda uji. Pada benda uji O0 kerusakan yang terjadi pada bagian atas beton dan sambungan CFRP lepas yang mengakibatkan kegagalan beton. Keseluruhan sambungan CFRP lepas hanya perbedaannya kerusakan CFRP pada bagian bawah tidak separah bagian atas. Bahkan pada baris pertama dan kedua, serat CFRP lepas hingga setengah lingkaran silinder. Pada benda uji $\mathrm{O} 2$ kerusakan beton cukup parah, terjadi retakan besar berupa garis diagonal dari atas hingga bawah, namun beton masih dapat menyatu karena tertahan oleh serat CFRP. Sedangkan untuk benda uji pengulangan lainnya kerusakan beton cukup parah hingga CFRP putus pada lapisan kedua. Berbeda dengan benda uji $\mathrm{O} 2$, pada benda uji $\mathrm{O} 3$ 
tidak ada serat CFRP yang putus pada masing-masing lapisannya, hanya sedikit lembaran-lembaran serat yang putus. Sehingga beton secara keseluruhan masih memiliki kekuatan, kerusakan terjadi pada cover beton bagian atas hingga setengah tinggi silinder. Untuk benda uji O7, kerusakan terjadi pada cover beton bagian atas yang diakibatkan oleh putusnya seratserat CFRP lapisan pertama.

Kerusakan cukup parah terjadi pada benda uji T2, beton bagian atas rusak hingga sekitar $5 \mathrm{~cm}$ ke tengah lingakaran bagian atas silinder. Serat CFRP lapisan atas putus. Kerusakan T3 adalah putusnya CFRP pada pada sambungannya dan memutihnya beberapa bagian serat CFRP di lapisan pertama hingga ketiga. Untuk benda uji T5, serat pada lapisan pertama dan kedua putus dan kerusakan bagian dalam beton sudah memasuki rusak beton bagian inti. Kerusakan beton paling parah terjadi pada benda uji TF. Serat CFRP yang dipasang full menutupi permukaan beton, putus hingga lebih dari setengah tinggi silinder. Dan beton bagian atas rusak hingga masuk ke inti beton.

\subsection{Hasil Kuat Tekan Umur 28 Hari}

Dari hasil uji tekan beton umur 28 hari maka diperoleh nilai kuat tekan beton terbesar adalah untuk benda uji dengan fully jacketing CFRP sebesar 23,02 MPa dengan peningkatan kuat tekan beton sebesar $32,54 \%$ terhadap beton normal BN. Secara rinci hasil kuat tekan beton dapat dilihat pada gambar 3 .

Nilai kuat tekan rata-rata beton umur 28 hari adalah 18,87 $\mathrm{MPa} ; 20,00 \mathrm{MPa}$; 21,89 MPa; 22,27 MPa; 22,65 MPa; 17,74 $\mathrm{MPa} ; 18,87 \mathrm{MPa}$; 20,38 $\mathrm{MPa}$ dan 23,02 MPa masing-masing untuk benda uji $\mathrm{BN}$, O0, O2, O3, O7, T2, T3, T5 dan TF.

Dengan prosentase peningkatan kuat tekan terhadap beton normal pada umur beton 28 hari adalah $6 \% ; 16 \% ; 18 \% ; 20 \%$; $2,12 \% ; 8,64 \% ; 17,33 \%$ dan $32,54 \%$ masing-masing untuk benda uji $\mathrm{O} 0, \mathrm{O} 2$, O3, O7, T2, T3, T5 dan TF. Jacketing full dengan CFRP terbukti mampu meningkatkan kuat tekan beton meskipun hasilnya tidak sebesar kemampuan CFRP menahan tarik atau daktilitas beton.

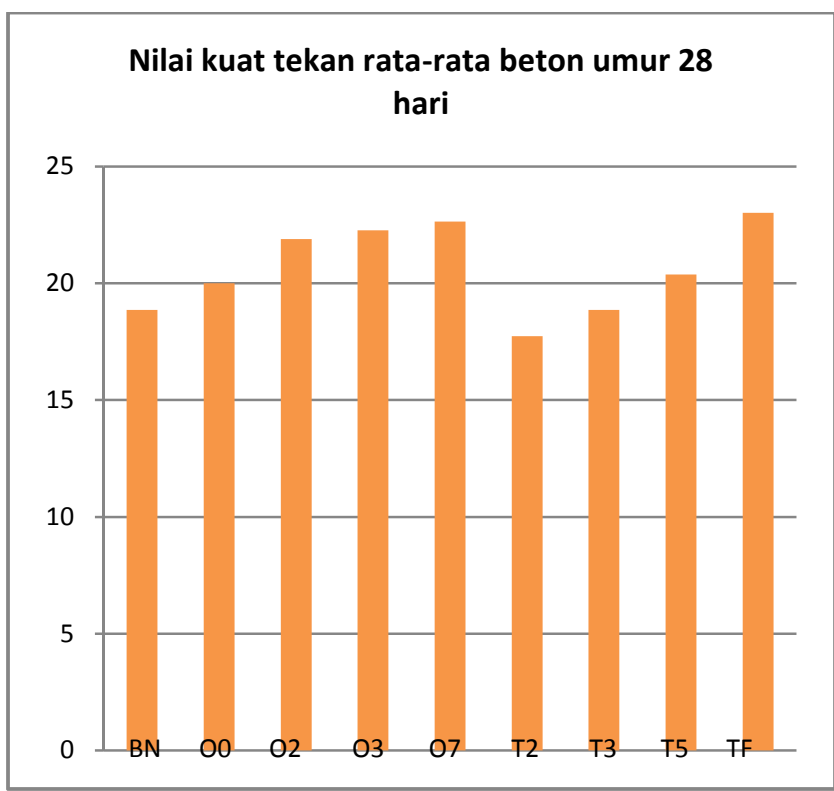

Gambar 3. Grafik Nilai Kuat Tekan Beton Umur 28 hari

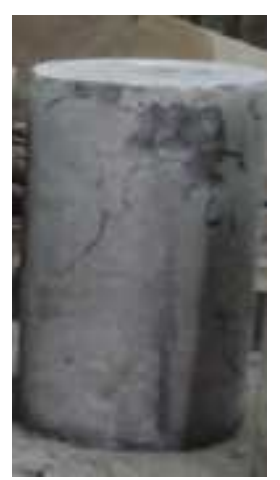

(a) $\mathrm{BN}$

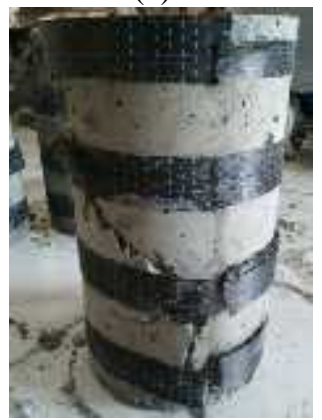

(b) $\mathrm{O} 0$ 


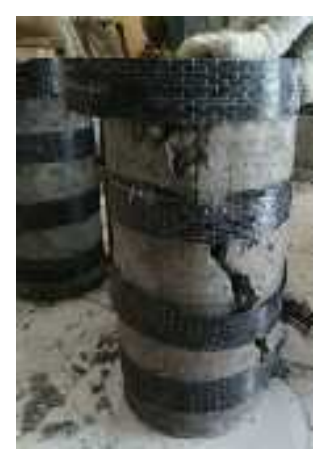

(c) $\mathrm{O} 2$

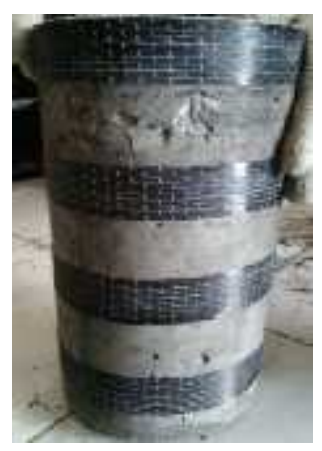

(d) $\mathrm{O} 3$

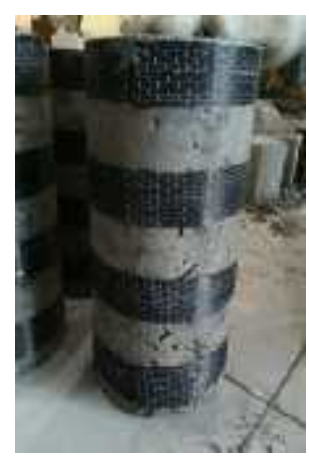

(e) $\mathrm{O} 7$

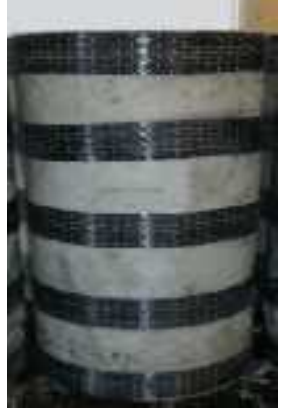

(f) $\mathrm{T} 2$

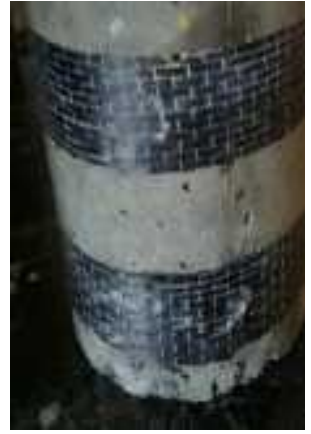

(g) $\mathrm{T} 3$

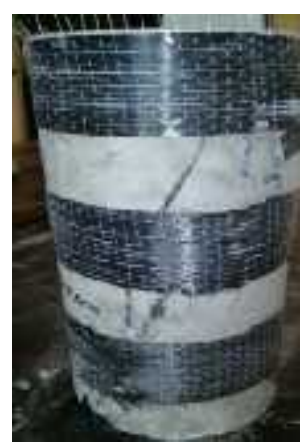

(h) $\mathrm{T} 5$

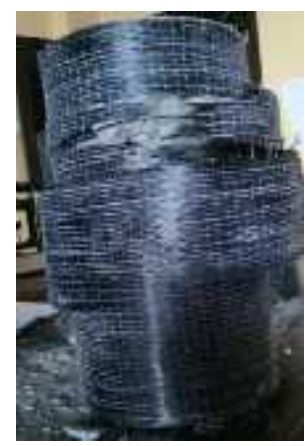

(i) $\mathrm{TF}$

Gambar 4. Hasil Pengujian 28 Hari

Mirip dengan kerusakan beton normal pada umur 14 hari maka kerusakan beton normal umur 28 hari, terjadi pada cover beton sepanjang tinggi benda uji. Kerusakan yang terjadi pada O0 berupa retak diagonal sepanjang tinggi silinder. Karena overlap pada benda uji adalah 0 $\mathrm{cm}$, maka seluruh sambungan CFRP terlepas. Pada benda uji O2 kerusakan yang terjadi mirip dengan kerusakan $\mathrm{O}$. kerusakan betonnya cukup parah, terjadi retakan besar berupa garis diagonal dari atas hingga bawah, namun beton masih dapat menyatu karena tertahan oleh serat CFRP. Dan kegagalan beton yang terjadi 
akibat putusnya serat-serat CFRP pada masing-masing lapisan. Berbeda dengan benda uji $\mathrm{O} 2$, pada benda uji $\mathrm{O} 3$ tidak ada serat CFRP yang putus pada masingmasing lapisannya, hanya terlihat sedikit garis-garis putih pada lembaran-lembaran CFRP namun serat CFRP belum putus. Kerusakan bagian cover beton terjadi pada sisi yang tidak dilapisi CFRP. Untuk benda uji O7, kerusakan terjadi pada cover beton dan masih tertahan dengan baik oleh lapisan CFRP.

Kerusakan yang terjadi pada benda uji T2 berupa banyaknya garis putih-putih pada serat CFRP dan kerusakan pada cover beton di bagian yang tidak dilapisi CFRP. Kerusakan yang terjadi pada benda uji T3 hampir sama dengan T2, yaitu kerusakan berupa berupa banyaknya garis putih-putih pada serat CFRP dan kerusakan pada cover beton di bagian yang tidak dilapisi CFRP. Untuk benda uji T5, terjadi retak diagonal sepanjang tinggi silinder dan serat CFRP putus di semua lapisan. Namun beton masih tertahan oleh CFRP yang masih utuh. Kerusakan beton paling parah terjadi pada benda uji TF. Serat CFRP yang dipasang full putus hingga lebih dari setengah tinggi silinder. Dan pada bagian dalam ternyata kondisi beton telah hancur. Beton masih bisa bertahan karena ada lapisan CFRP di keseluruhan permukaan benda uji. Ketika serat CFRP putus, kondisi beton didalamnya telah hancur.

\section{Kesimpulan}

Dari hasil uji tekan umur beton 28 hari dalam penelitian ini maka kesimpulan yang bisa ditarik adalah :

1. Penambahan partly jacketing CFRP pada beton dapat menambah kekuatan beton sebesar $6 \% ; 16 \% ; 18 \%$; 20\%; $2,12 \% ; 8,64 \% ; 17,33 \%$ terhadap $\mathrm{BN}$, masing-masing untuk benda uji $\mathrm{O} 0$, O2, O3, O7, T2, T3, T5.

2. Semakin besar tebal CFRP maka semakin besar kuat tekan beton yang dihasilkan, untuk benda uji T2, T3, T5 masing-masing sebesar : 17,74 $\mathrm{MPa}$; 18,87 MPa; 20,38 MPa.
3. Semakin besar overlaping CFRP maka semakin besar kuat tekan beton yang dihasilkan Nilai kuat tekan untuk benda uji O0, O2, O3, O7 berturutturut adalah: ; 20,00 MPa; 21,89 $\mathrm{MPa}$; 22,27 MPa; 22,65 MPa.

4. Besar kuat ekan pada benda uji fully jacketing (TF) adalah 23,02 $\mathrm{MPa}$ dengan peningkatan kuat tekan sebesar $32,54 \%$ terhadap beton normal.

\section{Saran}

Sehubungan dengan penelitian yang telah dilakukan terhadap beberapa saran yang dapat diberikan pada masa yang akan datang, saran-saran tersebut diantaranya :

1. Perlunya penambanhan pengulangan benda uji dalam masing-masing variasi agar data yang diperoleh valid

2. Dalam pemotongan CFRP harus dibuat pola pemotongan seoptimal mungkin untuk menghindari pembengkakan biaya yang dibutuhkan

3. Perlu penelitian lanjutan terkait optimalisasi peningkatan kuat tekan dan besar biaya yang dibutuhkan dalam pembuatan benda uji

4. Perlu penelitian lanjutan terkait pengaruh arah serat CFRP terhadap kuat tekan beton

\section{Daftar Pustaka}

[1] Badan Standardisasi Nasional. 2000. SNI 03-2834-2000Tata Cara Pembuatan Rencana Campuran Beton Normal. Jakarta

[2] Balaguru, P, Nanni, A and Giancaspro, J. 2009. "FRP Composites for Reinforced and Prestressed Concrete Structures" Taylor \& Francis Group, New York

[3] Gangarao et al. 2007. Reinforced Concrete Design with FRP Composites. CRC Press, London

[4] Lignola, GP. 2005. Confinement of RC Hollow Columns Using CFRP Laminates, Third International Conference Composite in Construction 
[5] Mulyono, Tri. 2003. Teknologi Beton.Yogyakarta: Penerbit Andi

[6] Sunarno. 2012. Penggunaan Pasir Samboja dan Kerikil dari Palu sebagai Bahan Pembuatan Beton Normal. Jurnal Ilmiah Politeknik Balikpapan vol 4, No.1, 2012 hal.

15-20 